\title{
Anthropogenic platinum enrichment in the vicinity of mines in the Bushveld Igneous Complex, South Africa
}

\author{
Sebastien Rauch ${ }^{1 \#}$, Olalekan S. Fatoki ${ }^{2}$ \\ ${ }^{1}$ Department of Civil and Environmental Engineering, Chalmers University of Technology, \\ 41296 Göteborg, Sweden \\ ${ }^{2}$ Faculty of Applied Sciences, Cape Peninsula University Technology, Cape Town, South \\ Africa \\ ${ }^{\#}$ Corresponding author. email address: Sebastien.rauch@chalmers.se
}

\begin{abstract}
South Africa is the world's single largest platinum $(\mathrm{Pt})$ producer owing to important resources in the Bushveld Igneous Complex (BIC). Little attention has been paid to the environmental impacts of mining in the region despite the extent of mining activities. Here, we present a study on the occurrence of Pt in the vicinity of mines in the BIC. Elevated concentrations were found at all sampling sites in the mining area. The highest Pt concentration in soil $(698 \pm$ $178 \mathrm{ng} \mathrm{g}^{-1},<125 \mu \mathrm{m}$ ) was found at a smelter, while processing plants, shafts and nearby towns had lower concentrations. Elevated Pt concentrations were also found in grass with a maximum of $256 \pm 122 \mathrm{ng} \mathrm{g}^{-1}$ at the smelter and a significant correlation between soil and grass concentrations. In comparison, $\mathrm{Pt}$ concentrations in soil and grass at a background site were $2.7 \pm 0.4 \mathrm{ng} \mathrm{g}^{-1}$ and $0.6 \pm 0.2 \mathrm{ng} \mathrm{g}^{-1}$, respectively. Laboratory uptake experiments indicate that atmospheric deposition is the main source of $\mathrm{Pt}$ in grass. The occurrence of elevated Pt concentrations and its accumulation in vegetation raise concern over exposure of the local population through inhalation, skin exposure or dietary intake.
\end{abstract}

Keywords: platinum, mining, smelter, South Africa, soil, grass, deposition. 


\section{Introduction}

The availability of abundant natural resources is a major component of the South African economy (Vermaak, 1997). Platinum $(\mathrm{Pt})$ is one of South Africa's most valuable resources owing to the general scarcity of this element in the Earth's crust (Peucker-Ehrenbrink and Jahn, 2001) and its increasing use (Johnson-Matthey, 2003). In 2010 South Africa produced 143 tons Pt, representing 76\% of the global Pt supply (Johnson-Matthey 2010).

South Africa's Pt resources are located in the Bushveld Igneous Complex (BIC), North of Pretoria (Figure 1). The BIC, which was formed by the repeated injection of lava (or magma) into a sub-volcanic, shallow-level chamber, is the world's largest mafic-ultramafic intrusion with an area of $65000 \mathrm{~km}^{2}$ and $75 \%$ of the world's Pt resources (Cawthorn, 1999). Pt is mainly mined from 2 ore layers, i.e. the Merinsky Reef and the Upper Group 2 (UG2) chromitite layer. Until recently, mining was concentrated on the Merinsky Reef in the western limb of the BIC because of higher grade, lower chromite content and easier access to mining sites. However, increasing demand and decreasing reserves have resulted in increasing mining of the deeper UG2 layer and of the eastern limb of the BIC. In 2006 mining of UG2 was expected to represent as much as $60 \%$ of the total ore processed in the BIC and $18 \%$ of the production was expected to take place in the eastern limb (Johnson-Matthey, 2003).

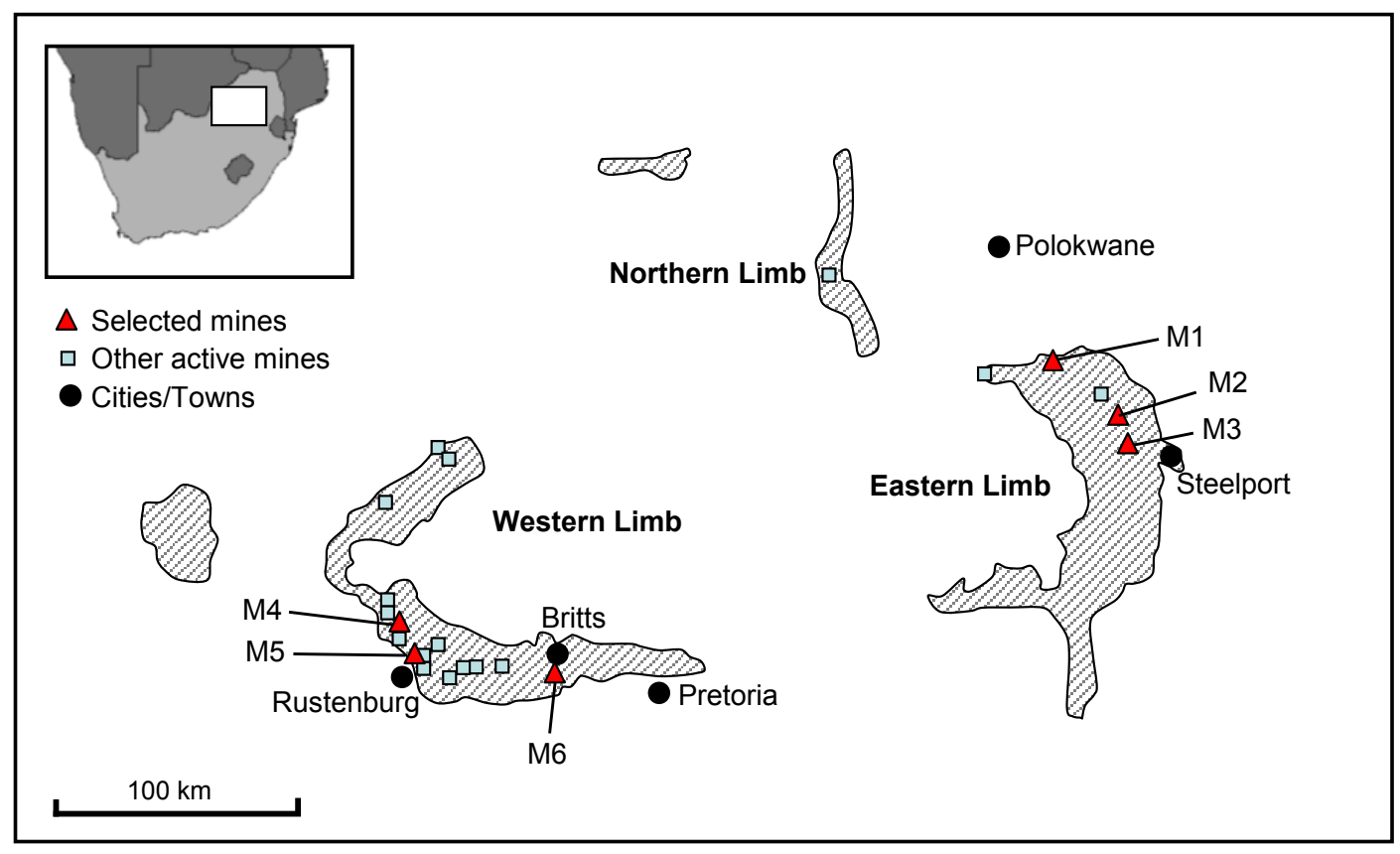

Figure 1. Schematic map of the Bushveld Igneous Complex with selected Pt mines.

Most of the South African Pt production is exported for use in jewellery, automobile exhaust catalysts and industrial applications (Johnson-Matthey, 2010). Studies on the environmental relevance of Pt have focused on urban environments where elevated Pt concentrations have been measured as a result of automobile catalyst emissions (Ravindra et al., 2004; Rauch and Morrison, 2008). Although metal production activities are recognised to be major sources of metals into the environment (Nriagu and Pacyna, 1988; Dudka and Adriano, 1997), potential Pt emissions from mining and ore processing have only drawn little interest until now. Studies in Russia have shown that smelters which process Pt-containing ores are an important source of Pt into the regional environment (Boyd et al., 1997; Gregurek et al., 1998; Gregurek et al., 1999; Niskavaara et al., 2004) and may contribute to the cycle of Pt in the Northern 
hemisphere (Rauch et al., 2005; Moldovan et al., 2007). The most significant risk from exposure to platinum is sensitization of the airways (Lindell, 1997). Exposure to platinum can also cause sensitization of skin. Mutagenic effects have been demonstrated in vitro, but genotoxic risks in humans remain uncertain (Lindell, 1997).

Mining and ore processing activities are major sources of sulfur dioxide and airborne particles in the BIC (Steyn, 2005). Air quality monitoring has recently been put in place in an effort to control emissions (Steyn, 2005), but potential Pt emission from mining and ore processing in the BIC has not been investigated. In this study, we investigate the hypothesis that mining activities are causing increased environmental Pt concentrations in the BIC and that local populations are exposed to this metal as a result of mining emissions.

\section{Experimental}

Soil and grass sampling

Soil and grass samples were collected in the vicinity of Pt mines in the BIC. Details of the sampling and location of selected mines are provided in Table 1 and Figure 1, respectively. Soil collection was performed using a gardening-type trowel and stainless steel scissors were use for grass collection. Samples were collected as close as possible to the mining complexes and at least $5 \mathrm{~m}$ from roads in order to limit the potential impact of automobile traffic emissions (Schäfer et al., 1999). All samples were kept in ziplock PE bags until return to the laboratory.

In a first step a screening was performed by the collection of soil samples at $6 \mathrm{Pt}$ mines (labelled M1-M6) in August 2006. To provide information relevant to the determination of the source of Pt, samples were obtained from the surface soil $(0-2 \mathrm{~cm})$ and from a deeper layer $(4-6 \mathrm{~cm})$. Further sampling was then performed at mine M4 (where the highest concentration was found during the screening) in August 2007 and December 2008. Surface soil $(0-2 \mathrm{~cm})$ was collected near an underground shaft, a processing plant and a smelter (2 samples), as well as in two towns (3 samples for town A and 2 samples for town B) located within $5 \mathrm{~km}$ of the smelter. In addition, grass (Aristida bipartita, Bothriochloa insculpta, Digitaria eriantha, Ischaemum afrum or Panicum maximum, depending on availability at the sampling site) was collected in August 2007.

\section{Uptake experiment}

Common oat (Avena sativa) was grown on selected, unsieved soil samples to assess potential Pt bioavailability. We note that all samples used in this study are true grasses (Poaceae) and the uptake experiment support the study of Pt bioavailability by plants, despite possible difference in uptake rate for different species. Soil samples used in the uptake experiment were collected in 2008 at mine M4 (near the smelter and the underground shaft) and in nearby towns. Approx. 10ml Milli-Q (18 M $\Omega \mathrm{cm}$, Millipore, USA) water were added daily. Obtained plants were harvested after 4 weeks and prepared as described below, along with respective soil samples.

\section{Samples preparation and analysis}

The soil samples were dried overnight at $105^{\circ} \mathrm{C}$ in acid washed beakers and were homogenised using a mortar and pestle. The samples were then sieved and the $<125 \mu \mathrm{m}$ fraction was retained for analysis. Selected soil samples were sieved into 5 fractions $(<125$ $\mu \mathrm{m}, 125-250 \mu \mathrm{m}, 250-500 \mu \mathrm{m}, 500-1000 \mu \mathrm{m}$ and $>1000 \mu \mathrm{m})$ and all fractions $<1000 \mu \mathrm{m}$ were analysed. Grass samples were thoroughly washed in Milli-Q water before drying to remove particles deposited onto the grass surface, dried overnight at $105^{\circ} \mathrm{C}$ and cut into small pieces using stainless steel scissors. 
The samples were prepared by closed-vessel microwave digestion (Mars5, CEM Corporation, Matthews, USA) using Aqua regia (3:1; $\mathrm{HCl}: \mathrm{HNO}_{3} ; \mathrm{v}: \mathrm{v} ; \mathrm{HCl}$, Suprapure grade, Merck, Darmstadt, Germany) as extractant. Approximately $0.5 \mathrm{~g}$ of soil or $0.3 \mathrm{~g}$ of grass were weighed into HP500 Teflon vessels and $8 \mathrm{ml}$ of Aqua regia were added to the samples. The temperature programme consisted of an $8 \mathrm{~min}$. ramp to $165^{\circ} \mathrm{C}$ followed by a 2-minute holding period and a second $5 \mathrm{~min}$. ramp to $175^{\circ} \mathrm{C}$ with a 5 -minute holding period with a maximum allowed pressure of 200 psi. The obtained solutions were transferred to Erlenmeyer flasks and slowly taken to dryness on a hotplate. The residues were dissolved in $10 \mathrm{ml} 2 \% \mathrm{HCl}$. Samples were kept at $8^{\circ} \mathrm{C}$ and diluted prior to analysis.

Platinum, $\mathrm{Cr}$ and $\mathrm{Cu}$ concentrations were determined by inductively coupled plasmamass spectrometry (ICP-MS, Elan6000, PE Sciex, Canada) using standard operating conditions (Rauch et al., 2001). Concentrations were determined by external calibration using Pt solutions prepared from single element standards (High Purity Standards, Promochem AB, Ulricehamn, Sweden) and multi-element standards for $\mathrm{Cr}$ and $\mathrm{Cu}$ (CertiPUR XI, Merck, Darmstadt, Germany). Interference from $\mathrm{HfO}$ on $\mathrm{Pt}$ was checked and corrected when necessary using a Hf standard (Parent et al., 1997; Rauch et al., 2001). Accuracy of the analytical procedure was checked for Pt using a road dust reference material (BCR-723, IRMM, Geel, Belgium) for which the measured Pt concentration was $75 \mathrm{ng} \mathrm{g}^{-1}$ for a certified concentration of $81.3 \pm 2.5 \mathrm{ng} \mathrm{g}^{-1}$. All results are presented as average \pm standard deviation.

\section{Results and discussion}

Average Pt concentrations for all analysed samples, including soil and grass collected at the background site, mining sites and nearby towns, are presented in Table 1.

Table 1. Pt concentration in soil and grass at selected mines and in towns in the vicinity of mine M4. Concentrations are presented as average \pm standard deviation.

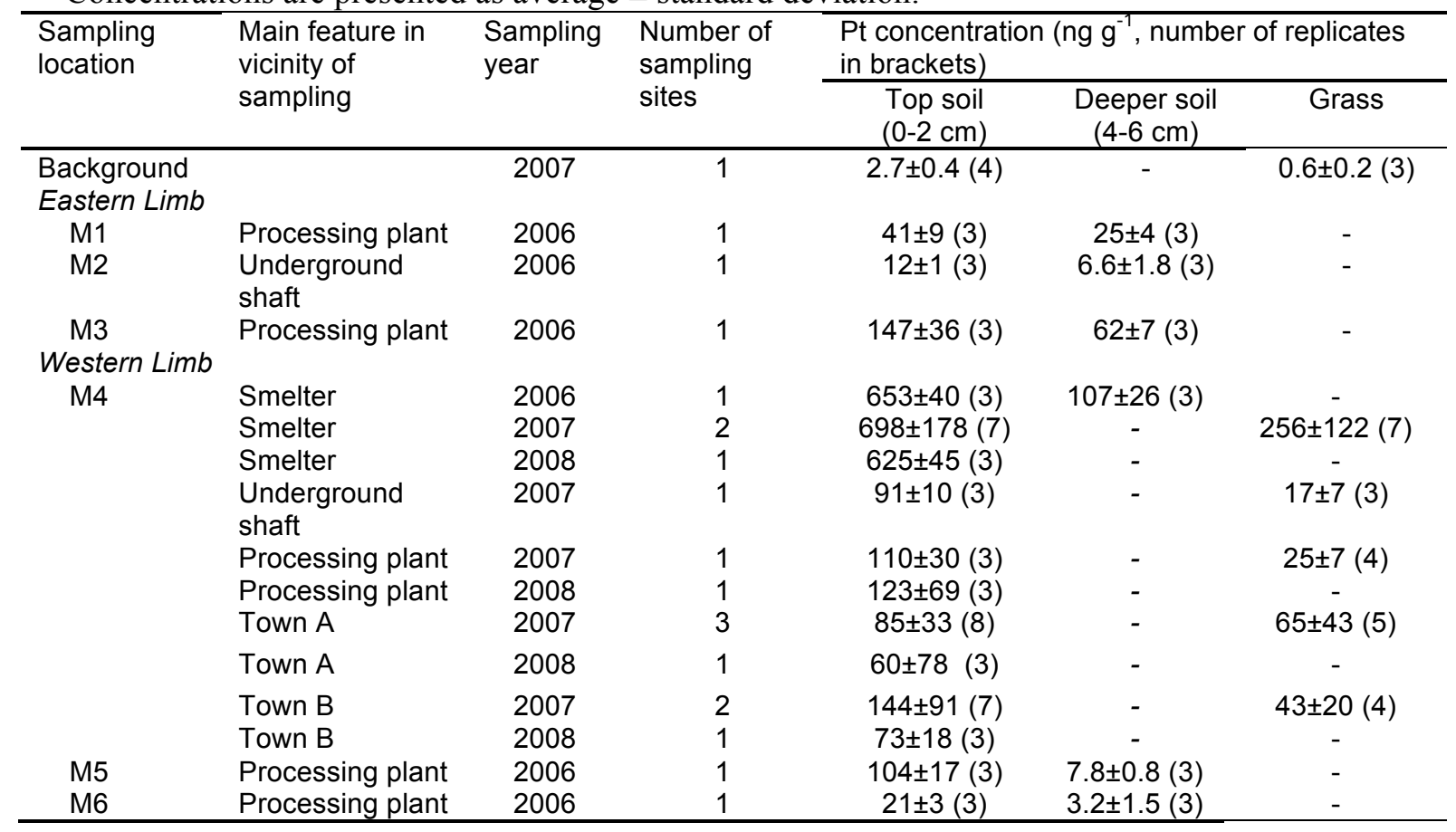


Pt concentrations in soil at mining sites

Platinum concentrations in top soil collected in the vicinity of selected mines in 2006 ranged from $9.9 \pm 0.7 \mathrm{ng} \mathrm{g}^{-1}$ near an underground shaft at M2 to $653 \pm 40 \mathrm{ng} \mathrm{g}^{-1}$ near a smelter at M4 (Figure 2). Significant contribution of the smelter to local Pt concentrations was confirmed by further sampling at mine M4 in 2007 and 2008. Concentration at the smelter was $698 \pm 178$ $\mathrm{ng} \mathrm{g}^{-1}$ in 2007 and $625 \pm 45 \mathrm{ng} \mathrm{g}^{-1}$ in 2008, whereas lower concentrations were found at a shaft and a processing plant at mine M4 (Figure 3). Platinum concentration at the smelter was approximately 250 times larger than at a background site where a concentration of $2.7 \pm 0.4$ $\mathrm{ng} \mathrm{g}^{-1}, 1400$ times larger than average upper continental crust (UCC) concentrations (PeuckerEhrenbrink and Jahn, 2001) and approximately 5 times lower than in Merenski Reef or UG2 ores (Cawthorn, 1999). In comparison, typical Pt concentrations in urban and roadside soil are in the 25-250 $\mathrm{ng} \mathrm{g}^{-1}$ range (Rauch and Morrison, 2008).

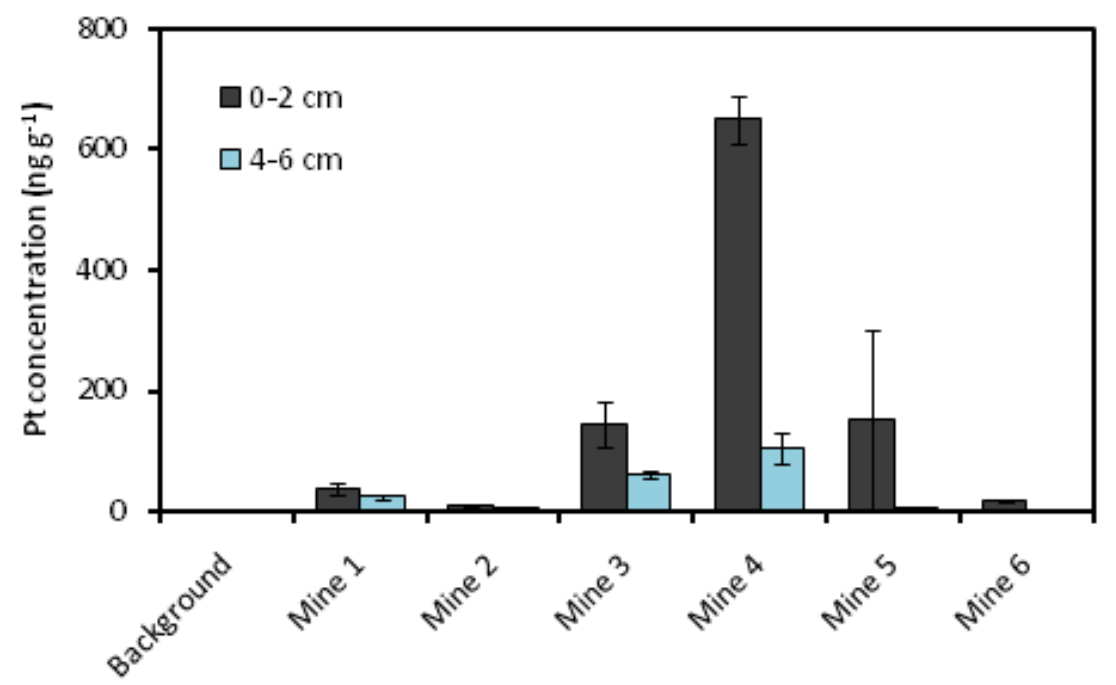

Figure 2. Platinum concentrations in soil $(<125 \mu \mathrm{m})$ collected at selected mines in 2006, including top soil $(0-2 \mathrm{~cm})$ and the deeper soil layer $(4-6 \mathrm{~cm})$. Background concentration obtained from samples collected in 2007 is provided for comparison. Error bars represent 1 standard deviation.

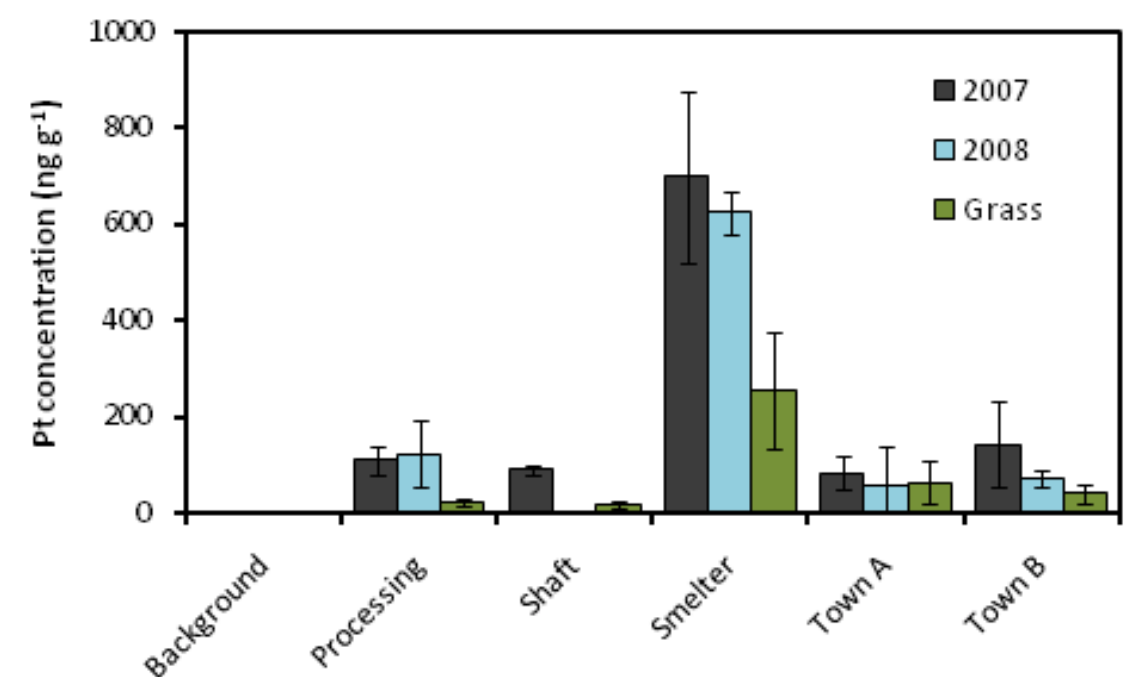

Figure 3. Platinum concentrations in soil $(<125 \mu \mathrm{m})$ and grass at mine M4 and in nearby towns for samples collected in 2007 and 2008. Error bars represent 1 standard deviation. 
Similarly high concentrations have been reported in the context of geochemical exploration. Platinum concentrations were found to exceed $180 \mathrm{ng} \mathrm{g}^{-1}$ in soil in part of the BIC including in the Rustenberg area and a causal relationship between Pt concentrations and mining operations has been suggested (Wilhelm et al, 1997). In addition, Pt concentrations measured in the BIC are in the same order as concentrations near plants processing Pt-containing ores in Russia. The average Pt concentration in topsoil from a catchment located $5 \mathrm{~km}$ South of the Monchegorsk plants was $49.6 \mathrm{ng} \mathrm{g}^{-1}$ with a maximum concentration of $466 \mathrm{ng} \mathrm{g}^{-1}$ (Boyd et al., 1997).

\section{Platinum concentrations in soil in nearby towns}

Soil samples collected in 2 towns located in the vicinity of mine M4 had elevated Pt concentrations relative to the background site. Platinum concentrations in Town A $(1 \mathrm{~km} \mathrm{~N}$ of the smelter) were $85 \pm 33 \mathrm{ng} \mathrm{g}^{-1}$ in 2007 and $60 \pm 78 \mathrm{ng} \mathrm{g}^{-1}$ in 2008. Concentrations in Town B (3 km SW of the smelter) were $144 \pm 91 \mathrm{ng} \mathrm{g}^{-1}$ in 2007 and $73 \pm 18 \mathrm{ng} \mathrm{g}^{-1}$ in 2008. These concentrations are approximately 20 to 50 fold higher than the measured background concentration and in the same order as at the processing plant and the underground shaft at mine M4 (Figure 3). There was no significant difference (T-test at 90\% confidence level) between soil concentrations in the two towns, despite Town B being further from the smelter, and no correlation between Pt concentrations and distance to the smelter $\left(\mathrm{R}^{2}=0.3\right)$.

\section{Source of Pt in soil and atmospheric dispersion}

Although elevated concentrations are often indicative of an anthropogenic source, elevated $\mathrm{Pt}$ concentrations in the BIC might also be the result of natural occurrence. To assess the source of $\mathrm{Pt}$ at selected mines, soil samples were collected at 2 depths $(0-2$ and 4-6 cm) in 2006. Average platinum concentrations were higher in the top soil layer $(0-2 \mathrm{~cm})$ than in the deeper layer $(4-6 \mathrm{~cm})$ at all mines (Figure 2). Although the soil layers are not dated, the higher concentrations in the top soil layers indicates a recent increase in Pt concentrations that may be linked to Pt mining and the reported increase in Pt production in the BIC (JohnsonMatthey, 2003).

Platinum concentrations in soil were found to vary with mining site (Figure 2), possibly due to differences in Pt production, mining activity and/or location of the sampling site relative to the mine. The smelter at M4, where the highest concentrations were found at two separate sampling sites, is the mine with the largest production volume. However, there is no correlation between soil concentrations at the different mines and Pt production, indicating that production volume only has a limited influence on soil concentrations. This is supported by variations at mine M4 (Figure 3) where the highest concentrations were found near the smelter. Russian smelters processing Pt-containing have been reported to be an important regional source of this metal (Gregurek et al., 1998; Gregurek et al., 1999; Niskavaara et al., 2004) and the high concentrations observed at the smelter (Figures 2 and 3) indicate that Pt smelters are an important source of Pt in the BIC. Other sources, including processing plants and shafts, also contribute to Pt emissions.

The particle size distribution of $\mathrm{Pt}$ at the smelter and the processing plant reveals differences in the source of Pt. The highest concentration at the smelter was found in the finest fraction $(<125 \mu \mathrm{m})$, whereas Pt was more evenly distributed between the different fractions at the processing plant (Figure 4). Ore processing essentially consists of milling and separation by flotation, and may therefore only result in the emission coarse particles. In contrast, smelting involves high temperature processes that may result in the formation of finer particles. The 
highest concentration in soil from nearby towns was measured in the smallest particle size fraction (Figure 4), indicating that the smelter contributes to elevated Pt levels in the towns. possibly due to the emission of $\mathrm{Pt}$ in fine particles.

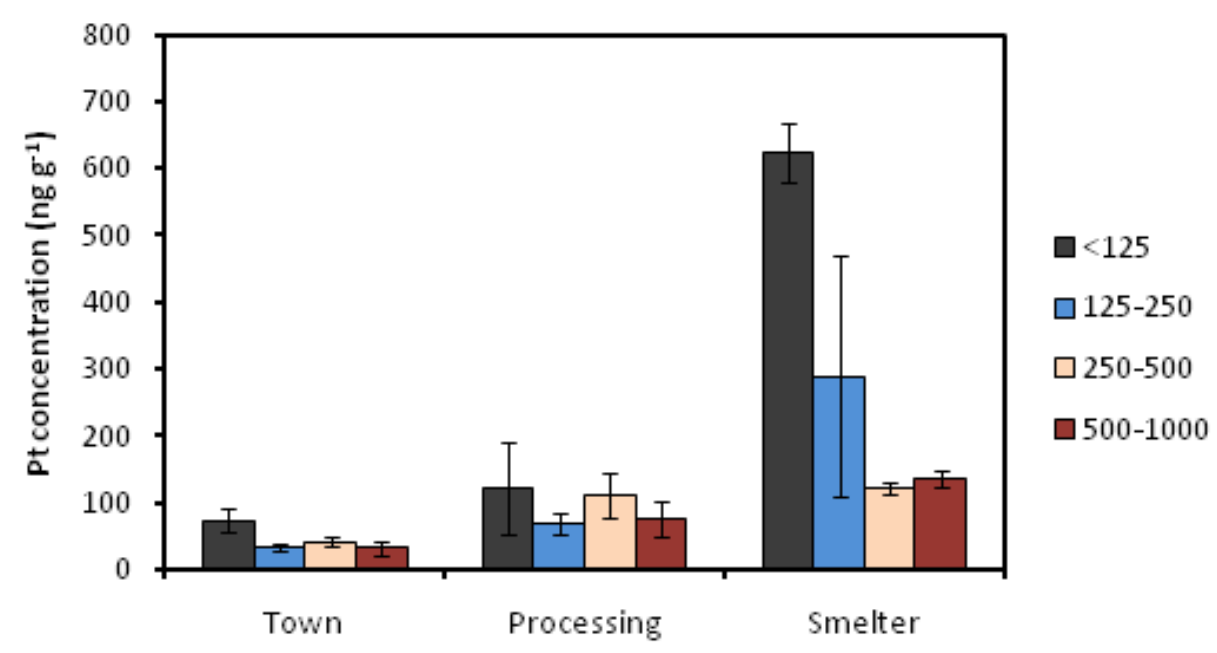

Figure 4. Particle size distribution (125 $\mu \mathrm{m} ; 125-250 \mu \mathrm{m} ; 250-500 \mu \mathrm{m} ; 500-1000 \mu \mathrm{m})$ of Pt in selected soil samples. Error bars represent 1 standard deviation.

Elevated concentrations in the nearby towns indicate an efficient atmospheric transport. Elevated Pt concentrations in road dust have been reported as far as Pretoria and have been attributed to atmospheric dispersion from Pt mines in the BIC (Rauch and Fatoki, 2010). Pretoria is located $>50 \mathrm{~km}$ from Pt mines in the BIC and $>100 \mathrm{~km}$ East of mine M4. These results support a widespread contamination and we suggest that the emission of fine $\mathrm{Pt}$ particles from the smelters in the BIC is resulting in the dispersion of $\mathrm{Pt}$ in the region.

\section{Platinum concentration in grass}

Elevated Pt concentrations were found in grass collected at mine M4 and in nearby towns in 2007 (Figure 3). The highest Pt concentration was measured near the smelter (256 $\pm 122 \mathrm{ng} \mathrm{g}^{-}$ $\left.{ }^{1}\right)$. Elevated Pt concentrations were also found in Towns A and B $\left(64 \pm 43 \mathrm{ng} \mathrm{g}^{-1}\right.$ and $43 \pm 20$ $\mathrm{ng} \mathrm{g}{ }^{-1}$, respectively). In comparison, a Pt concentration of $0.6 \pm 0.2 \mathrm{ng} \mathrm{g}^{-1}$ was measured at the background site. A significant correlation was found between Pt concentrations in soil and in grass, with grass concentrations approximately 3 times smaller than soil concentrations (Figure 5A). 
A

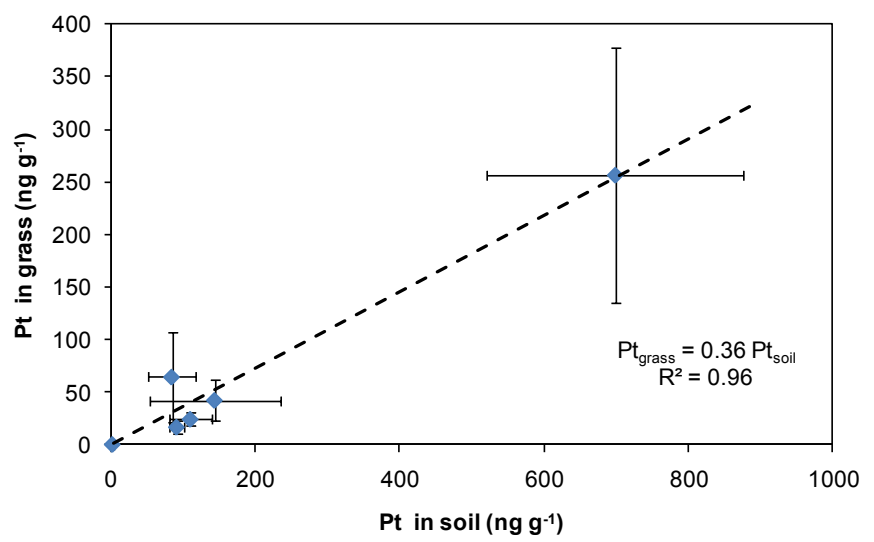

B

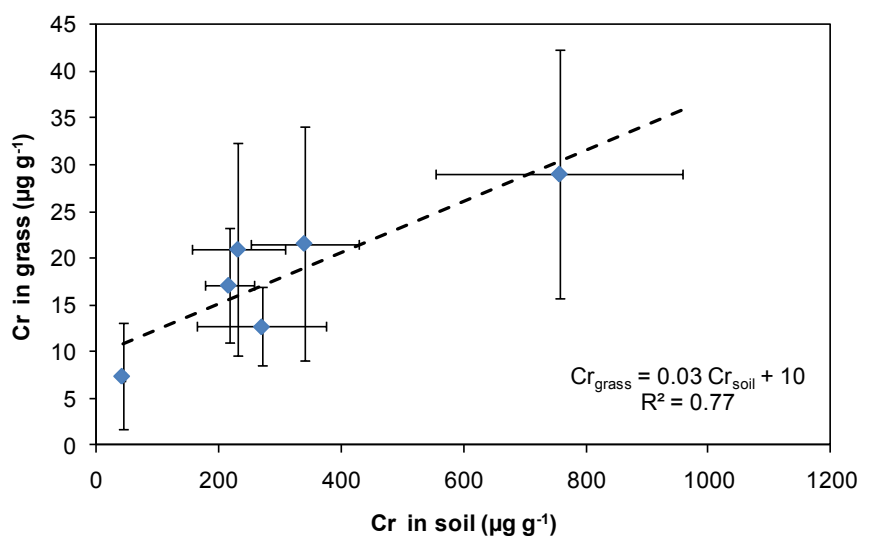

C

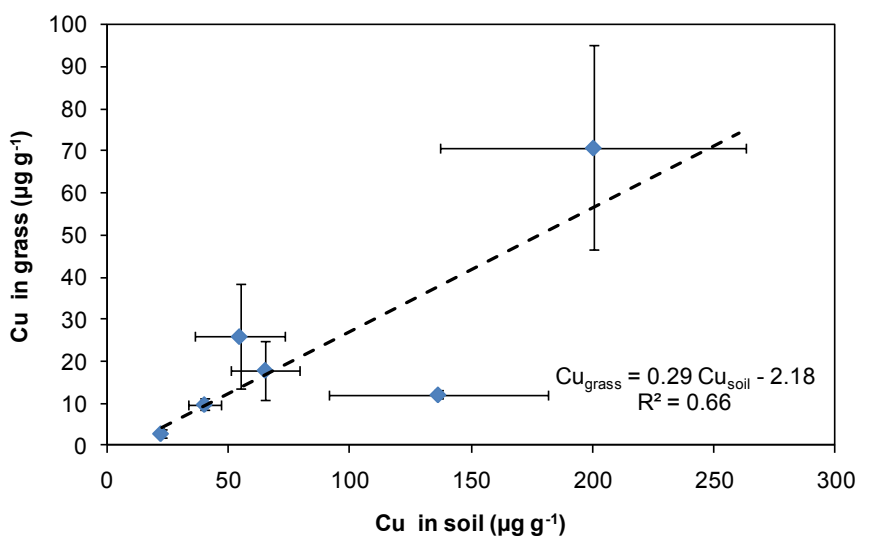

Figure 5. Correlation between $\mathrm{Pt}(\mathrm{A}), \mathrm{Cr}(\mathrm{B})$ and $\mathrm{Cu}(\mathrm{C})$ concentrations in soil and grass mine at $\mathrm{M} 4$, nearby towns and the background site. Error bars represent 1 standard deviation.

The occurrence of $\mathrm{Pt}$ in grass represents both atmospheric deposition and uptake from bioavailable $\mathrm{Pt}$ in soil. Studies on the occurrence of $\mathrm{Pt}$ in the roadside environment show that Pt emitted from automobile catalyst is bioavailable (Zimmermann and Sures, 2004; Ek et al., 2004). Platinum bioavailability was assessed in laboratory uptake experiments. Grass grown on soil collected near Pt mines contained elevated Pt concentrations with a significant correlation between soil and grass concentrations (Figure 6), but at concentrations much lower than in grass collected at the mining sites. These results indicate that atmospheric deposition is the main source of Pt in grass, while uptake of bioavailable Pt is likely to be a smaller contributor to Pt levels in grass at the mining sites. The occurrence of $\mathrm{Pt}$ in grass 
indicates that elevated Pt concentrations are also present in crops from local agricultural fields (approximately 400,000 $\mathrm{km}^{2}$ of cultivated land in the Rustenburg area (Steyn, 2005)) and gardens, raising concern over potential exposure through dietary intake.

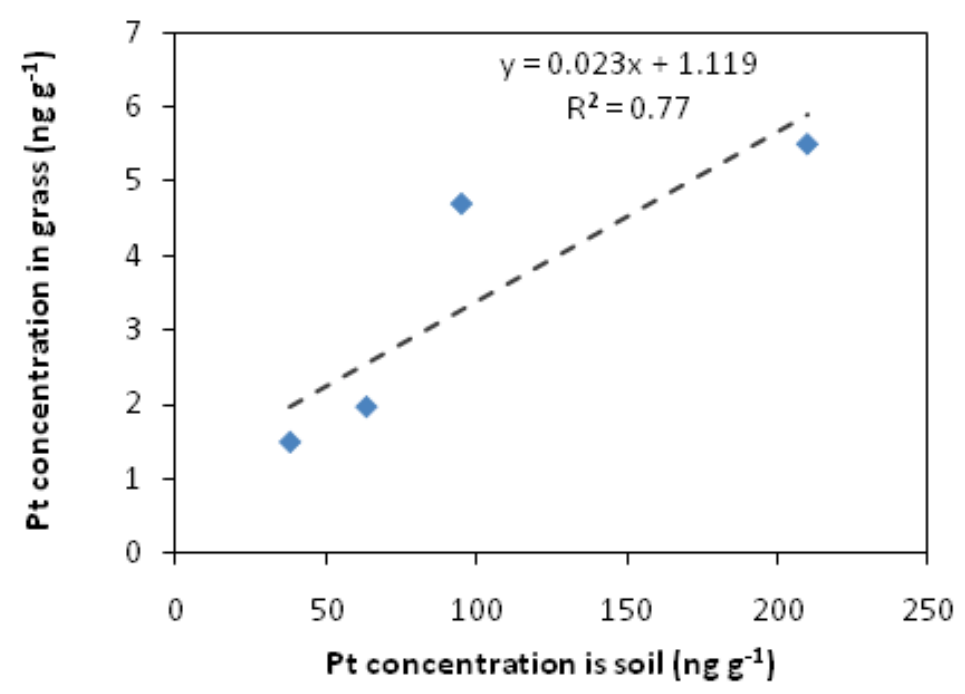

Figure 6. Platinum uptake by plants grown on selected unsieved soils. Presented soil concentrations correspond to the $<1000 \mu \mathrm{m}$ particle size fraction.

Comparison with copper and chromium

Chromium and copper were analysed in 2007 samples (Mine M4) because these elements might be associated with platinum emissions. Platinum is mined from chromium rich minerals (Cawthorn, 1999) and elevated $\mathrm{Cu}$ concentrations have been reported in soil from a tailing disposal facility at a South African Pt mine (Maboeta et al., 2006). Measured $\mathrm{Cr}$ and $\mathrm{Cu}$ concentrations are provided in Table 2. Copper and $\mathrm{Cr}$ concentrations were lowest at the background site and highest at the smelter. Positive correlations were found between $\mathrm{Pt}$ and $\mathrm{Cu}$ concentrations and between $\mathrm{Pt}$ and $\mathrm{Cr}$ concentrations in both soil and grass, indicating that mining is a common source for these elements. Chromium concentrations exceed expected values for uncontaminated soils (9.9-121 $\mu \mathrm{g} \mathrm{g}^{-1}$, Ali et al., 2004) at all sites, except the background site. In contrast, $\mathrm{Cu}$ concentrations do not exceed the expected values for uncontaminated soils $\left(2-250 \mu \mathrm{g} \mathrm{g}^{-1}\right.$, Ali et al., 2004) at any of the sites, indicating that $\mathrm{Cu}$ contamination by mining activities is more limited.

Table 2. Copper and chromium concentrations in top soil and grass at mine M4 and nearby towns in 2007 samples. Concentrations are presented as average \pm standard deviation.

\begin{tabular}{lccccc}
\hline Sampling location & Number of & \multicolumn{2}{c}{ Cu concentration $\left(\mu \mathrm{g} \mathrm{g}^{-1}\right)$} & \multicolumn{2}{c}{ Cr concentration $\left(\mu \mathrm{g} \mathrm{g}^{-1}\right)$} \\
\cline { 2 - 6 } & sampling sites & Top soil & Grass & Top soil & Grass \\
\hline Background & 1 & $22 \pm 1$ & $3 \pm 1$ & $43 \pm 3$ & $7 \pm 6$ \\
Smelter & 2 & $200 \pm 62$ & $71 \pm 24$ & $756 \pm 202$ & $29 \pm 13$ \\
Underground shaft & 1 & $40 \pm 7$ & $10 \pm 1$ & $217 \pm 40$ & $17 \pm 6$ \\
Processing plant & 1 & $136 \pm 45$ & $12 \pm 1$ & $340 \pm 87$ & $22 \pm 12$ \\
Town A & 3 & $55 \pm 19$ & $26 \pm 12$ & $271 \pm 105$ & $13 \pm 4$ \\
Town B & 2 & $65 \pm 14$ & $19 \pm 7$ & $232 \pm 76$ & $21 \pm 11$ \\
\hline
\end{tabular}


Positive correlations were also found between soil and grass concentrations for both $\mathrm{Cr}$ and $\mathrm{Cu}$ (Figure 5). The outlier for $\mathrm{Cu}$ corresponds to the processing plant and may be due to differences in soil properties or $\mathrm{Cu}$ speciation at this site. Similar slopes for $\mathrm{Cu}$ and $\mathrm{Pt}$ indicate that the accumulation rates for these two elements are similar, although accumulation mechanisms might be different. $\mathrm{Cu}$ is an essential element and therefore, similar accumulation rates indicates that $\mathrm{Pt}$ accumulation rates are relatively high.

\section{Conclusion}

Elevated Pt concentrations were measured in soil and grass in the vicinity of Pt mines in the BIC and were attributed to mining activities. Elevated Pt concentrations were also found in two towns located within a few $\mathrm{km}$ of a smelter where the highest Pt concentrations were measured. These results raise concern over exposure of the local population through inhalation, skin contact or dietary intake. Several towns and cities, including Rustenburg (400,000 inhabitants), and local food production activities are located in the Pt mining region. As Pt emissions are expected to increase as a result of the current expansion of Pt mining in the BIC, further work is needed to quantify Pt emissions from South African mines, understand the behaviour of these elements in the environment, characterise human exposure and determine its impact on the local population.

\section{Acknowledgements}

This research was funded by the Swedish International Development Agency (SIDA) under the Swedish Research Links programme and the South African National Research Foundation (NRF).

\section{References}

Ali NA, Ater M, Sunahara GI, Robidoux PY (2004) Phytotoxicity and bioaccumulation of copper and chromium using barley (Hordeum vulgare L.) in spiked artificial and natural forest soils. Ecotoxicol Environ Saf 57:363-374.

Boyd R, Niskavaara H, Kontas E, Chekushin V, Pavlov V, Often M, Reimann C (1997) Anthropogenic noble-metal enrichment of topsoil in the Monchegorsk area, Kola peninsula, northwest Russia. . Geochem Explor 58:283-289.

Cawthorn RG (1999) The platinum and palladium resources of the Bushweld Complex. South African J Sci 95:481-489.

Dudka S, Adriano DC (1997) Environmental impacts of metal ore mining and processing: A review. J Environ Qual 26:590-602.

Ek KH, Morrison GM, Rauch S (2004) Environmental routes for platinum group elements to biological materials - a review. Sci Total Environ 334:21-38.

Gregurek D, Melcher F, Niskavaara H, Pavlov VA, Reimann C, Stumpfl EF (1999) Platinumgroup elements (Rh, Pt, Pd) and Au distribution in snow samples from the Kola Peninsula, NW Russia. Atmospheric Environment 33:3281-3290.

Gregurek D, Reimann C, Stumpfl EF (1998) Trace elements and precious metals in snow samples from the immediate vicinity of nickel processing plants, Kola Peninsula, northwest Russia. Environ Pollut 102:221-232.

Johnson-Matthey (2003) The Expansion of Platinum Mining in South Africa. In: Platinum 2003. Johnson-Matthey, London, UK. pp 14-17.

Johnson-Matthey (2010) Platinum 2010. Johnson-Matthey, London, UK.

Lindell B (1997) DECOS and NEG basis for an occupational standard. Platinum. Arbetslivsinstitutet, Solna, Sweden. ISBN 91-7045-420-5. 
Maboeta MS, Claassens S, Van Rensburg L, Van Rensburg PJ (2006) The effects of platinum mining on the environment from a soil microbial perspective. Water Air Soil Pollut 175:149-161.

Moldovan M, Veschambre S, Amouroux D, Benech B, Donard OFX (2007) Platinum, palladium, and rhodium in fresh snow from the Aspe Valley (Pyrenees Mountains, France). Environ Sci Technol 41:66-73.

Niskavaara H, Kontas E, Reimann C (2004) Regional distribution and sources of Au, Pd and $\mathrm{Pt}$ in moss and O-, B- and C-horizon podzol samples in the European Arctic. Geochemistry-Exploration Environment Analysis 4:143-159.

Nriagu JO, Pacyna JM (1988) Quantitative assessment of worldwide contamination of air, water and soils by trace metals. Nature 333:134-139.

Parent M, Vanhoe H, Moens L, Dams R. (1997) Investigation of HfO+ interference in the determination of platinum in a catalytic converter (cordierite) by inductively coupled plasma mass spectrometry. Talanta 44:221-230.

Peucker-Ehrenbrink B, Jahn BM (2001) Rhenium-osmium isotope systematics and platinum group element concentrations: Loess and the upper continental crust. Geochemistry Geophysics Geosystems 2.

Rauch S, Hemond HF, Barbante C, Owari M, Morrison GM, Peucker-Ehrenbrink B, Wass U (2005) Importance of automobile exhaust catalyst emissions for the deposition of platinum, palladium, and rhodium in the Northern Hemisphere. Environ Sci Technol 39:8156-8162.

Rauch S, Fatoki OS (2010) Platinum and lead in South African road dust. In: Rauch S, Morrison GM, Monzon A. Highway and Urban Environment. Springer, Heidelberg. Germany. pp. 161-166.

Rauch S, Lu M, Morrison GM (2001) Heterogeneity of platinum group metals in airborne particles. Environ Sci Technol 35:595-599.

Rauch S, Morrison GM (2008) The environmental relevance of platinum group elements. Elements 4:259-263.

Ravindra K, Bencs L, Van Grieken R. (2004) Platinum group elements in the environment and their health risk. Science of the Total Environment 318: 1-43.

Schäfer J, Eckhardt JD, Berner ZA, Stüben D (1999) Time-dependent increase of trafficemitted platinum-group elements (PGE) in different environmental compartments. Environ Sci Technol 33:3166-3170.

Steyn S (2005) The C region of North West Province, South Africa. Doctoral thesis, University of Pretoria, South Africa.

Vermaak CF (1997) A brief overview of South Africa's mineral industry:world context and changing local circumstances. Mineralium Deposita 32:312-322.

Wilhelm HJ, Zhang H, Chen FL, Elsenbroek JH, Lombard M, deBruin D (1997) Geochemical exploration for platinum-group elements in the Bushveld complex, South Africa. Mineralium Deposita 32:349-361.

Zimmermann S, Sures B (2004) Significance of platinum group metals emitted from automobile exhaust gas converters for the biosphere. Environ Sci Pollut Res 11:194-199. 